\title{
Pola Kuman, Hasil Uji Sensitifitas Antibiotik dan Komplikasi Abses Leher dalam di RSUD DR. Soetomo
}

\author{
Denny Rizaldi Arianto*, Achmad Chusnu Romdhoni \\ Dept/SMF IImu Kes. Telinga Hidung Tenggorok Bedah Kepala dan Leher \\ Fakultas Kedokteran Universitas Airlangga / RSUD Dr. Soetomo Surabaya \\ *e-mail: 1
}

\begin{abstract}
Abstrak
Penelitian ini bertujuan untuk mendapatkan data lokasi, etiologi, hasil kultur kuman dan uji sensitifitas antibiotik serta komplikasi dari penderita abses leher dalam yang di rawat ruang rawat inap bedah teratai THT-KL RSUD Dr. Soetomo periode Januari sampai Desember 2014. Bahan dan metode penelitian yaitu rekam medik penderita. Hasil: Didapatkan 41 penderita. Lokasi di submandibula $13(31,70 \%)$, ruang peritonsil $11(26,82 \%)$, kombinasi ruang submandibula, parafaring dan retrofaring 11 (26,82\%). Etiologi infeksi gigi 14(34,14\%), infeksi tonsil akut 8(19,51\%), DM 8(19,51\%), DM Tipe 2 dan infeksi gigi 10(24,39\%), DM disertai infeksi orofaring $1(2,43 \%)$. Dari kultur pus didapatkan Staph. Aureus (33,33\%), Strep. viridians $(28,75 \%)$, Kleb. Pneumonia (9,52\%). Dari kultur darah didapatkan kuman Strep. viridians $(40,00 \%)$, Kleb. Pneumonia (20,00\%), Acinobacter humanii (20,00\%), Staph. Haemolyticus (20,00\%). Kultur urin didapatkan Acinobacter humanii dan Staph. haemolyticus masing-masing $50 \%$. Hasil uji sensitifitas antibiotik dari kultur pus didapatkan angka sensitive terhadap Meropenem (87,5\%), Ceftriaxone (73,68\%), Cefoperazone-sulbactam $(70,00 \%)$, Cefotaxime $(68,75 \%)$. Resitensi kuman terhadap antibiotika tersebut diatas secara berurutan $12,50 \%$, $21,05 \%, 20,00 \%, 12,5 \%$. Komplikasi sepsis $12(29,26 \%)$, obstruksi jalan napas atas (trakeotomi) $6(14,63 \%)$. Kesimpulan: Lokasi tersering di submandibula disusul peritonssil, kombinasi submandibula dan parafaring atau retrofaring. Etiologi tersering infeksi gigi disusul tonsil. Penyakit penyerta tersering yaitu DM. Kuman yang sering ditemukan dari kultur pus adalah Staph. aureus dan Strep. viridians. Kuman dari kultur darah terbanyak Strep. viridians, disusul Kleb. pneumonia, Acinobacter humanii, Staph. haemolyticus. Hasil uji sensitifitas terhadap antibiotik dari kultur pus didapatkan angka sensitif tertinggi adalah Meropenem disusul Ceftriaxone, Cefoperazone-sulbactam dan Cefotaxime. Komplikasi tersering sepsis disusul obstruksi jalan nafas atas dan mediastinitis. Sebanyak $4,87 \%$ penderita meninggal.
\end{abstract}

Kata Kunci: Abses leher dalam, kultur kuman, uji sensitifitas antibiotik, komplikasi.

\section{Germs Patterns, Results of Antibiotic Sensitivity and Complications in Deep Neck Abscess at DR. Soetomo General Hospital}

\begin{abstract}
The aim of this study was to obtain location data, etiology, results of germ culture and antibiotic sensitivity testing as well as complications from patients with deep neck abscesses treated by ENT-KL lotus surgery in Dr. RSUD Hospital. Soetomo from January to December 2014. Materials and research methods are medical records of patients. Results: Obtained 41 patients. Location in submandibular 13 (31.70\%), 11 peritonsil space (26.82\%), combination of submandibular space, parafaring and retrofaring 11 (26.82\%). Etiology of tooth infection 14
\end{abstract}


Pola Kuman, Hasil Uji Sensitifitas Antibiotik dan Komplikasi Abses Leher dalam di RSUD DR...

Denny Rizaldi Arianto, Achmad Chusnu Romdhoni

(34.14\%), acute tonsil infection 8 (19.51\%), DM 8 (19.51\%), Type 2 DM and tooth infection 10 (24.39\%), DM accompanied by oropharyngeal infection 1 (2.43\%). Staph obtained from the culture of pus. aureus (33.33\%), Strep. viridians (28.75\%), Kleb. pneumonia (9.52\%). From blood cultures Strep germs are obtained. viridians (40.00\%), Kleb. Pneumonia (20.00\%), Acinobacter humanii (20.00\%), Staph. Haemolyticus (20.00\%). Urine culture was obtained by Acinobacter humanii and Staph. haemolyticus 50\% each. The results of the antibiotic sensitivity test from pus culture showed a number of sensitivity to Meropenem (87.5\%), Ceftriaxone (73.68\%), Cefoperazone-sulbactam (70.00\%), Cefotaxime (68.75\%). The germ resistance to antibiotics mentioned above is $12.50 \%, 21.05 \%, 20.00 \%, 12.5 \%$ respectively. Complications of sepsis 12 (29.26\%), upper airway obstruction (tracheotomy) 6 (14.63\%). Conclusion: The most common location in the submandibula is peritonssyl, a combination of submandibular and parafaring or retrofaring. The most common aetiology of dental infections is followed by tonsils. The most common comorbid disease is DM. Germs that are often found from pus culture are Staph. aureus and Strep. viridians. The bacteria from the most blood cultures Strep. viridians, followed by Kleb. pneumonia, Acinobacter humanii, Staph. haemolyticus. The results of the sensitivity test on antibiotics from pus culture showed that the highest sensitive number was Meropenem followed by Ceftriaxone, Cefoperazone-sulbactam and Cefotaxime. The most common complication of sepsis is followed by upper airway obstruction and mediastinitis. As many as $4.87 \%$ of sufferers died.

Keywords: Deep neck abscess, germ culture, antibiotic sensitivity test, complications

\section{PENDAHULUAN}

$\begin{array}{cccc}\text { Abses leher dalam adalah } \\ \text { terkumpulnya nanah } & \text { (pus) di ruang }\end{array}$ potensial diantara fasia leher dalam. Tumpukan pus ini terjadi sebagai akibat perluasan dari berbagai keradangan misalnya infeksi gigi, faring, tonsil, sinus paranasal dan telinga atau akibat trauma. Gejala dan tanda klinik berupa nyeri dan pembengkakan di ruang leher dalam yang terkena. Secara anatomi ruang potensial leher dalam merupakan daerah yang sangat kompleks. Agar dapat melakukan penanganan abses leher dalam secara baik diperlukan pengetahuan tentang anatomi dari ruang potensial leher dalam (Gadre and Gadre, 2006; Fachruddin, 2007; Abshirini et al, 2010). Kejadian abses leher dalam menurun secara drastis sejak era antibiotik. Saat ini belum diketahui secara pasti angka kejadian abses leher dalam di berbagai rumah sakit besar di Indonesia. Sebelum era antibiotik, $70 \%$ infeksi leher dalam berasal dari penyebaran infeksi di faring dan tonsil ke parafaring. Saat ini infeksi leher pada anak dalam lebih sering berasal dari tonsil, sedangkan orang dewasa oleh karena infeksi gigi dan diabetes melitus (Murray and Marcincuk, 2013; Yang et al, 2008).

Kuman penyebab abses leher dalam biasanya terdiri dari campuran kuman aerob, anaerob dan fakultatif anaerob. Penelitian oleh Asmar di India mendapatkan hasil kultur abses retrofaring dari $90 \%$ penderita ditemukan kuman 
aerob, dan $50 \%$ penderita ditemukan juga kuman anaerob (Buyten, 2005). Penanganan abses leher dalam berupa insisi drainase abses dan pemeriksaan, kultur kuman dari pus dan uji kepekaan antibiotik. Hasil pemeriksaan ini memerlukan waktu yang cukup lama, sehingga biasanya diberikan antibiotik berdasarkan data empiris (Buyten, 2005).

Tujuan penelitian ini adalah hendak mendapatkan data penderita abses leher dalam yang di Ruang Rawat Inap Bedah Teratai THT-KL RSUD Dr. Soetomo selama periode Januari sampai Desember 2014 meliputi lokasi, etiologi, hasil kultur kuman dan uji sensitifitas antibiotik serta komplikasinya.

\section{BAHAN DAN METODE}

Penelitian ini menggunakan desain retrospektif deskriptif. Sampel diambil dari data sekunder berasal dari rekam medik penderita abses leher dalam di ruang Rawat Inap Ruang Bedah Teratai THT-KL RSUD. Dr. Soetomo Surabaya periode Januari-Desember 2014.

\section{HASIL DAN PEMBAHASAN}

Didapatkan 41 penderita,Laki-laki 31 $(75,60 \%)$ dan perempuan 10 (24,40\%). Umur termuda 8 tahun, tertua 71 tahun. Terbanyak 46-60 tahun yaitu 13 (31,70\%). Dari 41 penderita tersebut, diperole data sebagai berikut:

Tabel 1. Lokasi abses leher dalam

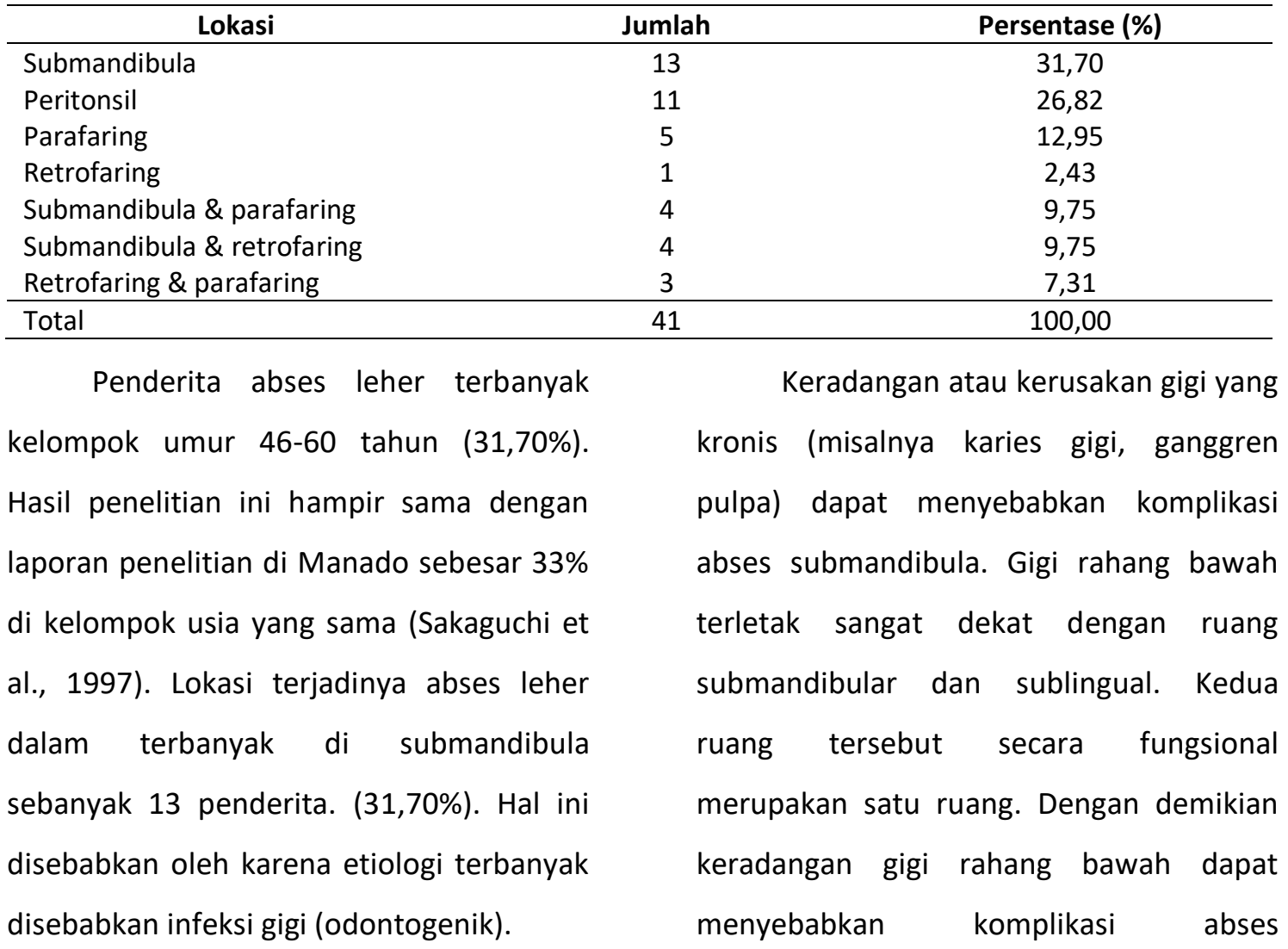


Pola Kuman, Hasil Uji Sensitifitas Antibiotik dan Komplikasi Abses Leher dalam di RSUD DR...

Denny Rizaldi Arianto, Achmad Chusnu Romdhoni

submandibula.Terkumpulnya pus di ruang submandibula selanjutnya meluas ke ruang disekitarnya (Boyanova et al, 2006). Pada penelitian ini ada 8 penderita $(19,51 \%)$ abses submandibula telah meluas ke parafing dan retrofaring. Perluasan pus menuju ke arah bawah menuju rongga parafaring dan retrofaring sering terjadi oleh karena lokasinya yang berdekatan. Mekanisme perluasan abses dari ruang submandibula ke parafaring dan retrofaring oleh karena tekanan (kontraksi) otot dasar mulut yang seakan mendorong pus menuju ke rongga parafaring dan retrofaring.

Abses submandibula dan parafaring maupun abses submandibila dan retrofaring dapat terjadi secara bersamaan. Pada penelitian ini didapatkan abses submandibula dan parafaring pada 4 penderita $(9,75 \%)$, abses submandibula dan retrofaring 4 penderita $(9,75 \%)$. Prosentase terjadinya perluasan abses submandibula ke sekitarnya ini lebih kecil dibandingkan temuan peneliti lain yang melaporkan angka sebesar 30\% (Huang et al, 2004). Hasil yang sama dilaporkan Huang et al (2004), di Cina mendapatkan kasus abses leher dalam yang meliputi beberapa ruang potensial leher sebesar $12 \%$ penderita. Seringnya terjadi perluasan abses oleh karena letak ruang potensial leher yang saling berdekatan (Huang et al, 2004; Brook, 2002).

Abses peritonsil didapatkan sebanyak 11 penderita (26,82\%). Abses peritonsil ini merupakan komplikasi dari tonsillitis akut. Pus yang terletak di kripte magna tonsil dapat meluas menuju ke lateral sehingga berada di ruang peritonsil. Tumpukan pus diruang peritonsil menyebabkan tonsil terdorong ke arah medioinferior (Jason et al, 2010).

Abses parafaring didapatkan sebanyak 5 pasien $(12,95 \%)$ dan abses retrofaring hanya didapatkan pada 1 penderita $(2,43 \%)$. Abses parafaring dan retrofaring dijumpai pada 3 penderita (7,31\%). Abses parafaring dan retrofaring dapat merupakan infeksi tersendiri maupun sebagai perluasan dari abses peritonsil dan abses submandibula.

Tabel 2. Etiologi

\begin{tabular}{lcc}
\hline \multicolumn{1}{c}{ Etiologi } & Jumlah & Persentase (\%) \\
\hline Infeksi gigi / Odontogenik & 14 & 34,14 \\
Infeksi tonsil akut & 8 & 19,51 \\
DM Tipe 2 & 8 & 19,51 \\
DM Tipe 2 \& odontogenik & 10 & 24,39 \\
DM Tipe 2 \& infeksi orofaring & 1 & 2,43 \\
\hline Total & 41 & 100,00 \\
\hline
\end{tabular}


Penyebab timbulnya abses leher dalam kebanyakan tersebut berasal dari infeksi gigi sebesar 34,1\%. Hal ini dimungkinkan karena disaat usia muda penderita kurang menjaga kesehatan gigi sehingga dengan berjalan waktu timbulnya infeksi gigi kronis yang menyebakan timbulnya komplikasi abses. Dikatakan bahwa tidak ada batasan umur pada abses submandibula (Chuang and Wang, 2006) (Parhiscar and Har-El, 2001). Sumber infeksi paling sering pada abses leher dalam berasal dari infeksi gigi (odontogenik) sebanyak 14 penderita $(34,1 \%)$, sedangkan yang disebabkan DM 8 penderita (19,51\%).

Hasil penelitian ini hampir sama dengan laporan Hesly dkk di RSU. Prof. dr. R D Kandau Menado mendapatkan infeksi gigi sebanyak 31\% dan DM sebanyak 37\%. Hasil yang sama juga dilaporkan oleh Novialdi di RSU. Dr M. Djamil Padang mendapatkan infeksi gigi $37 \%$ dan DM 43\%. Infeksi gigi dapat mengenai pulpa dan periodontal. Penyebaran infeksi dapat melalui pulpa atau foramen apikal gigi ke daerah sekitarnya. Apek gigi molar I yang berada di atas muskulus milohioid menyebabkan penjalaran infeksi akan masuk terlebih dahulu ke ruang sublingual, sedangkan molar II dan III apeknya berada di bawah muskulus milohioid sehingga infeksi akan lebih cepat ke ruang submandibula (Brook, 2002).Abses leher dalam yang diderita oleh penderita diabetes mellitus disebabkan karena terjadi penurunan sistim imunitas (immunocompromised) sehingga perlawanan terhadap kuman menurun, berakibat infeksi yang semakin hebat (AlSabah et al, 2004).

Tabel 3. Hasil kultur kuman (spesimen pus, darah dan urin)

\begin{tabular}{lcccccc}
\hline \multicolumn{1}{c}{ Hasil Kultur Kuman } & Pus & \% & Darah & $\%$ & Urin & $\%$ \\
\hline Staphylococcus aureus & 7 & 33,33 & - & - & - & - \\
Streptococcus viridians & 6 & 28,75 & 2 & 40,00 & - & - \\
Klebsiella pneumonia & 2 & 9,52 & 1 & 20,00 & - & - \\
Streptococcus non haemolyticus & 1 & 4,76 & - & - & - & - \\
Streptococcus acidominumus & 1 & 4,76 & - & - & - & - \\
Streptococcus anginosus & 1 & 4,76 & - & - & - & - \\
Streptococcus uberis & 1 & 4,76 & - & - & - & - \\
Staphylococcus hominis & 1 & 4,76 & - & - & - & - \\
Streptococcus oralis & 1 & 4,76 & - & - & - & - \\
Acinobacter humanii & - & - & 1 & 20,00 & 1 & 50,00 \\
Staphylococcus haemolyticus & - & - & 1 & 20,00 & 1 & 50,00 \\
\hline Total & 21 & 100,00 & 5 & 100,00 & 2 & 100,00 \\
\hline
\end{tabular}


Pola Kuman, Hasil Uji Sensitifitas Antibiotik dan Komplikasi Abses Leher dalam di RSUD DR... Denny Rizaldi Arianto, Achmad Chusnu Romdhoni

Pada umumnya abses leher dalam disebabkan oleh infeksi campuran beberapa kuman aerob, anaerob maupun fakultatif anaerob. Pada penelitian ini dilakukan kultur kuman aerob saja, tidak dilakukan kultur kuman anaerob. Kuman aerob yang paling sering ditemukan dari kultur pus adalah Staphylococcus aureus $(33,33 \%)$ disusul kemudian Streptococcus viridians $(28,75 \%)$ dan Klebsiella pneumonia (9,52\%). Sedangkan dari kultur darah yang terbanyak Streptococcus viridians $(40,00 \%)$, sedangkan Klebsiella pneumonia, Acinobacter humanii, Staphylococcus haemolyticus masingmasing $20,00 \%$. Kuman yang ditemukan dari kultur urin didapatkan Acinobacter humanii dan Staphylococcus haemolyticus masing-masing $50 \%$.

Berbagai kuman ini sebenarnya merupakan flora normal yang sering dijumpai di rongga mulut (orofaring). Pada penderita dengan penurunan sistem imun, kuman ini akan menjadi patogen dan menembus mukosa rongga mulut yang berakibat terjadinya infeksi (Parhiscar and Har-El, 2001; Boyanova et al, 2006).

Hasil penelitian ini berbeda dengan laporan hasil penelitian Novialdi di RSU Dr. M. Djamil Padang periode April-Oktober 2010 yang mendapatkan jenis kuman Streptocccus a haemoliticus (37\%),
Klebsiella sp (25\%), Enterobacter sp (19\%), Staphylococcus aureus (12,5\%), Staphylococcus epidermidis (6\%), E. Coli (6\%) dan Proteus vulgaris (6\%). Perbedaan pola kuman ini dapat disebabkan oleh karena banyak faktor antara lain jenis dan seringnya pemberian antibiotik tertentu, gizi, sistem imunitas, etnis dan penyakit penyerta. Pada kebanyakan infeksi gigi, ditemukan kuman anaerob lebih banyak daripada kuman aerob dan fakultatif anaerob dengan perbandingan mulai 10:1 sampai 10000:1. Beberapa peneliti melaporkan kuman yang paling dominan di gigi adalah kuman anaerob antara lain Prevotella, Porphyromonas, Fusobacterium spp, dan Peptostreptococcus spp, sedangkan kuman aerob yang sering ditemukan adalah Streptococcus pyogenic dan Stapylococcus aureus (Sakaguchi et al, 1997). Peneliti lain melaporkan kuman aerob yang sering ditemukan adalah Staphylococcus, Streptococcus sp, Haemofilus influenza, Streptococcus Peneumonia, Moraxtella catarrhalis, Klebsiell sp, Neisseria $s p$. Kuman anaerob yang sering adalah Peptostreptococcus, Fusobacterium dan Bacteroides sp (AlSabah et al, 2004; Poe et al, 1996). 
Tabel 4. Hasil uji sensitifitas terhadap antibiotik

\begin{tabular}{lcccc}
\hline \multicolumn{1}{c}{ Antibiotik } & $\boldsymbol{\Sigma}$ & $\mathbf{S}$ & $\mathbf{I}$ & $\mathbf{R}$ \\
\hline Ampicillin & 17 & $8(47,05 \%)$ & $3(17,64 \%)$ & $6(35,29 \%)$ \\
Ampicillinn-sulbactam & 16 & $6(37,50 \%)$ & $5(31,25 \%)$ & $5(31,25 \%)$ \\
Erytromicin & 16 & $9(56,25 \%)$ & $1(6,25 \%)$ & $6(37,50 \%)$ \\
Cefixime & 14 & $9(64,28 \%)$ & $1(7,14 \%)$ & $4(28,57 \%)$ \\
Chloramphenicol & 16 & $9(56,25 \%)$ & $3(25,00 \%)$ & $4(25,00 \%)$ \\
Cotrimoxazole & 12 & $7(58,33 \%)$ & $3(25,00 \%)$ & $2(16,66 \%)$ \\
Cefotaxime & 16 & $11(68,75 \%)$ & $3(18,75 \%)$ & $2(12,50 \%)$ \\
Gentamycin & 13 & $7(53,84 \%)$ & $1(7,69 \%)$ & $5(38,46 \%)$ \\
Ciprofloxacin & 17 & $10(58,82 \%)$ & 0 & $7(41,17 \%)$ \\
Ceftriaxone & 19 & $14(73,68 \%)$ & $1(5,26 \%)$ & $4(21,05 \%)$ \\
Ceftazidime & 18 & $11(61,11 \%)$ & $4(22,22 \%)$ & $3(16,66 \%)$ \\
Cefoperazone & 14 & $8(57,14 \%)$ & $2(14,28 \%)$ & $4(28,57 \%)$ \\
Cefoperazone-sulbactam & 10 & $7(70,00 \%)$ & $1(10,00 \%)$ & $2(20,00 \%)$ \\
Meropenem & 16 & $14(87,50 \%)$ & 0 & $2(12,50 \%)$ \\
Moxifloxacine & 12 & $7(58,33 \%)$ & $2(16,66 \%)$ & $3(25,00 \%)$ \\
\hline
\end{tabular}

Keterangan: S: Sensitif; I: Intermediate; R: Resisten

$$
\text { Pada penelitian ini semua }
$$
penderita mendapatkan pengobatan berupa insisi abses. Secara ideal, pemilihan antibiotik berdasarkan hasil biakan kuman dan tes kepekaan antibiotik terhadap kuman penyebab infeksi. Hasil biakan kuman dan tes kepekaan antibiotik membutuhkan waktu yang agak lama, sedangkan antibiotik harus segera diberikan. Oleh karena itu pemilihan antibiotik yang diberikan biasanya berdasarkan data empiris. Penanganan abses leher dalam di Ruang Rawap Inap Bedah Teratai THT-KL RSUD Dr. Soetomo biasanya diberikan kombinasi Cefriaxone dan Metronidazole. Hasil uji sensitifitas terhadap antibiotik dari kultur pus didapatkan angka sensitif tertinggi adalah Meropenem sebesar 87,5\%, disusul kemudian Ceftriaxone 73,68\%, Cefoperazone-sulbactam 70,00\%, Cefotaxime $68,75 \%$. Sedangkan resitensi kuman terhadap antibiotika tersebur diatas secara berurutan 12,50\%, 21,05\%, 20,00\%,12,5\%. Dengan demikian pemberian Ceftriaxone di Ruang Rawap Inap Bedah Teratai THT-KL RSUD Dr. Soetomo sudah sesuai dengan hasil uji sensitifitas antibiotik.

Hasil penelitian Boyanova et al (2006) berdasarkan uji kepekaan antibiotik yang dilakukan pada kuman anaerob didapatkan angka resistensi terhadap amoksisilin sebesar 26,7\%. Sedangkan klindamisin dan metronidazole terhadap gram negatif anaerob masing-masing sebesar $5,4 \%$ dan 2,5\%. Terhadap gram positif masing-masing $4,5 \%$ dan $58,3 \%$ (Buyten, 2005). Dengan demikian metronidazole dan klindamisin merupakan pilihan utama untuk membunuh kuman anaerob. Berbagai kombinasi pemberian antibiotik secara empiris yang dianjurkan berdasarkan hasil kepekaan kuman yang 
Pola Kuman, Hasil Uji Sensitifitas Antibiotik dan Komplikasi Abses Leher dalam di RSUD DR...

Denny Rizaldi Arianto, Achmad Chusnu Romdhoni

dilaporkan oleh berbagai peneliti yaitu

Ceftriaxone dan Clindamycin, Cefuroxime dan Metronidazole, Penisilin Gentamisin, Flucloxacine, Metronidazole (Novialdi and Pulungan, 2010).

Berbagai hasil penelitian yang dilaporkan menunjukkan bahwa kombinasi antibiotik yang terbaik berdasarkan data empirik yaitu kombinasi CeftriaxoneClindamycin. Selama ini penicilin G merupakan obat terpilih untuk infeksi bakteri Streptococcus dan Staphylococcus yang tidak menghasilkan enzim penisilinase. Gentamisin menunjukkan efek sinergis dengan penicilin. Clindamycin efektif terhadap Streptococcus, pneumokokus dan Staphylococcus yang resisten terhadap penicilin. Pemberian Clindamycin sangat dianjurkan pada infeksi polimicrobial termasuk Bacteroides $s p$ maupun bakteri anaerob lainnya pada daerah oral. Bila hasil kultur didapatkan kuman anaerob, maka antibiotik Metronidazole, Clindamycin, Carbapenem, Cefoksitin, atau kombinasi penicilin dan $\beta$ lactam inhibitor (Chuang and Wang, 2006; Boyanova et al, 2006).

Metronidazole juga efektif sebagai amubisid. Aminoglikosida, Quinolone atau

Tabel 5. Komplikasi

\begin{tabular}{lcc}
\hline \multicolumn{1}{c}{ Komplikasi } & Jumlah & Persentase (\%) \\
\hline Sepsis & 12 & 54,54 \\
Obstruksi jalan napas atas (Trakeotomi) & 6 & 27,27 \\
Mediastinitis & 4 & 18,18 \\
\hline & 22 & 100,00 \\
\hline
\end{tabular}

Cefalosforin generasi ke III dapat ditambahkan jika terdapat bakteri enterik gram negatif (Jason et al, 2010). Cefalosporin generasi III mempunyai efektifitas yang lebih baik terhadap gram Cefalosporin generasi I, generasi III kurang efektif terhadap kokus gram positif, tapi sangat efektif terhadap Haemofillus infeluenza, Neisseria sp dan Pneumokokus. Ceftriaxone dan Cefotaxime mempunyai efektifitas terhadap Streptococcus. Ceftriaxone sangat efektif terhadap gram negatif dan Haemophillus sp. Kebanyakan Streptococcus pneumonia dan Neisseriae $s p$ resisten terhadap penicillin (Al-Sabah et al, 2004). Bila uji kepekaan antibiotik terhadap kuman penyebab telah didapatkan maka diberikan antibiotik yang sesuai. Pada pemberian kombinasi antibiotik secara empiris jika terdapat perbaikan, maka antibiotik dapat diteruskan. Namun apabila tidak ada pertumbuhan kuman maka antibiotik diganti sesuai uji sensitifitas antibiotik (Jason et al, 2010; Poe et al, 1996). negatif enterik. Dibanding dengan 
Dari hasil penelitian ini dapatkan perbandingan laki-laki dan perempuan sebesar 3:1 dengan keseluruhan 41 penderita. Hasil penelitian ini berbeda dengan penelitian tentang abses submandibula di Manado didapatkan perbandingan sebesar 1:1 (Sakaguchi et al, 1997). Hasil penelitian di Cina sebesar 3:2,6 (Brook, 2002). Insiden abses leher dalam lebih banyak ditemukan pada laki-laki dibanding perempuan. Kemungkinan hal ini disebabkan laki-laki kurang memperhatikan kebersihan rongga mulut khususnya gigi geligi dibanding perempuan (Huang et al, 2004) (Brook, 2002).

Pada penelitian ini didapatkan komplikasi tersering berupa sepsis $(29,26 \%)$, obstruksi jalan napas atas sehingga dilakukan trakeotomi (14,63\%) dan mediastinis $(9,75 \%)$. Ada 2 penderita $(4,87 \%)$ meninggal dunia akibat sepsis. Penderita abses leher dalam yang disertai sepsis biasanya disertai penyakit penyerta yang sering diketemukan adalah diabetes melitus. Pada penderita DM terjadi penurunan fungsi respon imun yang mengakibatkan lebih mudah terkena berbagai macam infeksi. Apabila terkena infeksi cenderung infeksi makin hebat hingga sepsis. Pada penderita DM terjadi berbagai komplikasi antara lain proses angiopati, penurunanan fungsi endotel dan gangguan fungsi organ vital.
Penatalaksanaan abses leher dalam pada penderita DM harus dilakukan dengan hatihati, karena tindakan invasif tanpa pengendalian gula darah dapat berakibat infeksi semakin hebah, sepsis dan kematian (Poe et al, 1996).

\section{KESIMPULAN}

Penderita abses leher dalam yang dirawat di Ruang Rawat Inap Bedah Teratai THT-KL RSUD Dr. Soetomo Surabaya periode Januari sampai Desember 2014 kebanyakan laki laki, kelompok umur terbanyak 46-60 tahun. Lokasi tersering di submandibula disusul peritonsil. Kombinasi tersering adalah abses submandibula dan parafaring atau retrofaring. Etiologi tersering yaitu infeksi gigi disusul tonsil. Penyakit penyerta tersering yaitu DM. Kuman yang sering ditemukan dari kultur pus adalah Staphylococcus aureus dan Streptococcus viridians. Kuman dari kultur darah terbanyak Streptococcus viridians, disusul Klebsiella pneumonia, Acinobacter humanii, Staphylococcus haemolyticus. Hasil uji sensitifitas terhadap antibiotik dari kultur pus didapatkan angka sensitif tertinggi adalah Meropenem disusul Ceftriaxone, Cefoperazone-sulbactam dan Cefotaxime. Komplikasi tersering yaitu sepsis disusul obstruksi jalan nafas atas dan mediastinis. Sebanyak 2 penderita meninggal oleh karena sepsis berat. 
Pola Kuman, Hasil Uji Sensitifitas Antibiotik dan Komplikasi Abses Leher dalam di RSUD DR...

Denny Rizaldi Arianto, Achmad Chusnu Romdhoni

Berdasarkan penelitian ini disarankan kepada masyarakat untuk menjaga kesehatan gigi dan mengatur pola makan agar resiko menderita DM menjadi berkurang.

\section{DAFTAR PUSTAKA}

Abshirini H, Alavi SM, Rekabi $H$ and Ghazipur A, 2010. Predisposing Factors for The Complications of Deep Neck Infection. The Iranian J of Otorhinolaryngol. 22(60):45139.

Al-Sabah B, Bin Salleen H, Hagr A, ChoiRosen J, Manoukian JJ, Tewfik TL, 2004. Retropharyngeal Abscess in Children: 10-year study. J Otolaryngol. 33(6):352-355.

Boyanova L, Kolarov R, Gergova G, Deliverska E, Madjarov J, Marinov M, Mitov I, 2006. Anaerobic Bacteria in 118 Patient with Deep Space Head and Neck Infections from the University of Hospital of Maxillofacial Surgery, Sofia, Bulgaria. J Med Microbiol. 55(Pt 9):1285-1289.

Brook I, 2002. Microbiology of Polymicrobial Abscesses and Implication for Therapy. J Antimicrob Chemother. 50(6):805-810.

\author{
Buyten J, 2005. Deep Neck Space \\ Infections. \\ https://www.utmb.edu/otoref/gr \\ nds/deep-neck-infection- \\ 051005/deep-neck-infection-pics- \\ 051005.pdf.
}

Chuang YC and Wang HW, 2006. A Deep Neck Abscess Presenting as a Hypopharyngeal Carcinoma. J Med Sci. 26(5):183-186.

Fachruddin D, 2007. Abses Leher Dalam: Buku Ajar Ilmu Penyakit Telinga Hidung Tenggorok. 6th ed. Jakarta: Balai Penerbit FK-UI.

Gadre AK and Gadre KC, 2006. Infection of the Deep Space of The Neck: Otolaryngology Head and Neck Surgery. $4^{\text {th }}$ ed. Philadelphia: JB.Lippincott Company.

Huang TT, Liu TC, Chen PR, Tseng FY, Yeh TH, Chen YS, 2004. Deep Neck Infection: Analysis of 18 Cases. Head and Neck. 26(10):854-860.

Jason A, McKellop JA and Mukherji SK, 2010. Emergency Head and Neck Radiology: Neck Infection. [Online] Murray AD and Marcincuk MC, 2013. Deep Neck Infections. [Online] Available at: http://www.eMedicine Specialties//Otolaringology and facial plastic surgery.com. 
ISSN 1978-2071 (Print); ISSN 2580-5967 (Online) Jurnal IImiah Kedokteran Wijaya Kusuma 8(1) : 88-98, Maret 2019

Novialdi dan Pulungan MR, 2010. Pola Kuman Abses Leher Dalam. Repository UNAND.

Parhiscar A and Har-El G, 2001. Deep Neck Abscess: A Retrospective Review of 210 Cases. Ann Otol Rhinol Laryngol. 110(11):1051-1054.

Poe LB, Petro GR and Matta I, 1996.

Percutaneous $\quad$ CT-Guided

Aspiration of Deep Neck Abscesses. ANJR Am J Neurodiol. 17(7):1359-1363.
Sakaguchi M, Sato S, Ishiyama T, Katsuno S, Taguchi K, 1997. Characterization and Management of Deep Neck Infection. J. Oral Maxillofac Surg. 26(2):131-134.

Yang SW, Lee MH, See LC, Huang SH, Chen TM, Chen TA, 2008. Deep Neck Abscess: An Analysis of Microbial Etiology and Effectiveness of Antibiotics. Infection and Drug Resistance. 1:1-8 